\title{
Sellar inflammatory mass with inflammatory bowel disease
}

\author{
Hugh J Freeman MD, John Maguire MD
}

HJ Freeman, J Maguire. Sellar inflammatory mass with inflammatory bowel disease. Can J Gastroenterol 2009;24(1): 58-60.

Inflammatory bowel disease may be associated with different intracranial disorders. An inflammatory sellar mass is very rare but includes a variety of noninfectious causes including lymphocytic hypophysitis, granulomatous inflammation and Wegener's granulomatosis. A 32-year-old man was diagnosed with an inflammatory sellar mass associated with an extensive colonic inflammatory process clinically characteristic of Crohn's disease. The concurrent onset of these inflammatory disorders in distinctly separate sites may reflect their common embryological origin or represent an unusual form of metastatic Crohn's disease. Further studies are needed to determine if less overt or focal sellar inflammatory processes occur in inflammatory bowel disease, particularly in Crohn's disease because their occurrence may be critically relevant for long-term management.

Key Words: Crohn's disease; First Nations; Granulomatous inflammation; Inflammatory bowel disease; Metastatic Crohn's disease; Pituitary sella

$\Lambda \mathrm{n}$ inflammatory sellar mass or pseudotumour of the pitu- 1 itary sella is very rare; however, a dramatic clinical response to medical treatment with corticosteroids may occur (1). The differential diagnosis of inflammatory sellar lesions is difficult, relies primarily on histological analysis and, in addition to infectious causes (eg, tuberculosis), includes other nonneoplastic disorders such as lymphocytic hypophysitis, granulomatous inflammation (ie, sarcoidosis) and Wegener's granulomatosis (2). Clinical effects related to the sellar lesion may include either neurological or endocrinological features, or both. Interestingly, however, these non-neoplastic disorders may rarely be associated with intestinal disease and positive cytoplasmic-staining antineutrophil cytoplasmic antibody (c-ANCA) (eg, Wegener's granulomatosis with intestinal involvement) (3-5).

The present report documents the unusual, clinical, simultaneous occurrence of two apparently distinct clinicopathological disorders - specifically, a sellar inflammatory mass associated with an intermittently symptomatic inflammatory process characteristic of Crohn's disease involving the colon alone for more than a decade. Interestingly, while the two sites for this concomitant inflammatory process were quite separate, their relationship may be more than coincidental, with potential therapeutic implications for the future management of inflammatory bowel disease.

\section{Masse sellaire inflammatoire accompagnant une maladie inflammatoire de l'intestin}

La maladie inflammatoire de l'intestin est parfois associée à différentes affections intracrâniennes. Les masses sellaires inflammatoires sont très rares et leurs étiologies non infectieuses sont diverses, notamment l'hypophysite lymphocytaire, l'inflammation granulomateuse et la granulomatose de Wegener. On a posé chez un homme de 32 ans un diagnostic de masse sellaire inflammatoire associée à un processus inflammatoire du côlon cliniquement étendu et caractéristique de la maladie de Crohn. Le déclenchement simultané des deux processus inflammatoires dans des foyers distincts pourrait indiquer leur origine embryologique commune ou représenter une forme inhabituelle de maladie de Crohn métastatique. D’autres études seront nécessaires pour vérifier si la maladie inflammatoire de l'intestin, particulièrement la maladie de Crohn, peut s'accompagner d'un processus inflammatoire sellaire moins apparent, ou se manifestant en foyers, car cela pourrait revêtir une importance considérable dans la prise en charge à long terme de la maladie.

\section{CASE PRESENTATION}

A 32-year-old First Nations man first developed waxing and waning headaches that coincided with intermittent diplopia in 1997. An ophthalmologist diagnosed a right sixth cranial nerve paresis. In August 2000, the patient's headaches progressively became more severe, and were associated with diplopia on right-sided gaze. He became photophobic, with nausea and vomiting. Computed tomography and magnetic resonance imaging scans at a community hospital showed an enhancing clivus lesion with increased tissue density in the sphenoid sinus. Although cultures were negative, ceftriaxone, metronidazole and gentamicin were administered for four weeks. His headache improved but never completely resolved. Another magnetic resonance imaging scan scan showed a persistent clivus lesion, but the sphenoid density resolved.

In January 2001, recurrent, localized, right frontal and retroorbital headaches developed, with nausea, vomiting, photophobia and horizontal diplopia on rightward gaze. There were no other neurological symptoms or evidence of altered endocrine function. Transphenoidal biopsy showed sphenoid sinus mucosa along with bone and soft tissue from the clivus. The sphenoid sinus biopsy revealed a polypoidal lesion with predominantly chronic inflammation. The bone showed reactive changes, with areas of increased osteoclastic activity. Sinusoidal mucosa and fragments of lamellar bone were seen. The mucosal

Departments of Medicine (Gastroenterology) and Anatomical Pathology (Neuropathology), University of British Columbia, Vancouver, British Columbia

Correspondence: Dr Hugh Freeman, Division of Gastroenterology, 2211 Wesbrook Mall, Vancouver, British Columbia V6T 1 W5.

Telephone 604-822-7216, fax 604-822-7236, e-mail hugfree@shaw.ca

Received for publication January 16, 2009. Accepted January 21, 2009 


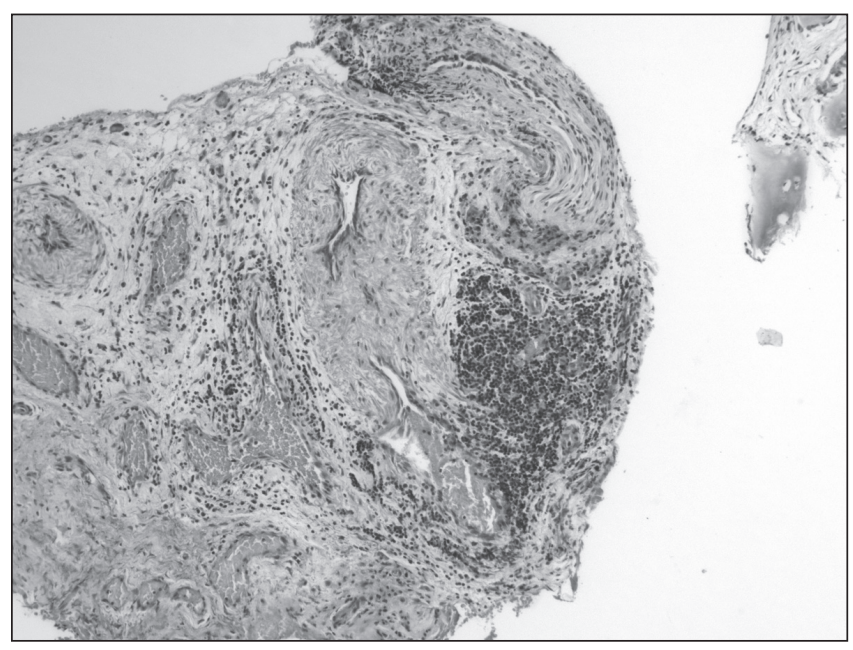

Figure 1) Nasopharyngeal submucosa showing intense reactive lymphocytic infiltrate (hematoxylin and eosin stain, original magnification $\times 100$ )

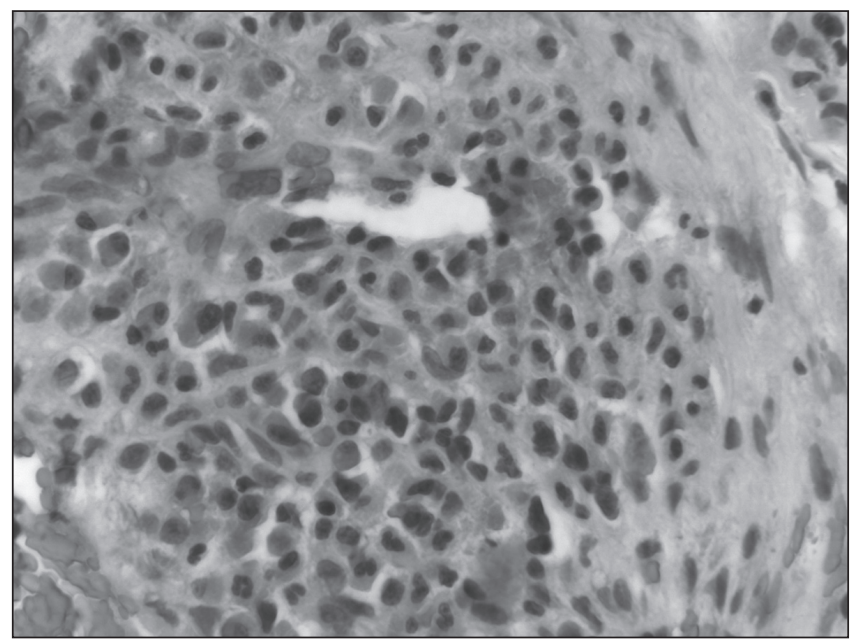

Figure 2) Submucosal infiltrate of plasma cells, eosinophils and lymphocytes (hematoxylin and eosin stain, original magnification $\times 400$ )

tissue was lined by respiratory-type epithelium and formed papillary structures. The stroma contained infiltrates of lymphocytes and plasma cells. Focal areas of calcification were seen. Pathological interpretation was predominantly chronic inflammation, with bone showing reactive changes (Figures 1 and 2). He was transferred to the Vancouver Hospital, University of British Columbia (Vancouver, British Columbia) in March 2001, for a right frontotemporal craniotomy and clival biopsies. Cultures were negative, including acid-fast organisms. Chest radiographs were normal and a tuberculosis skin test was negative. Serum angiotensin-converting enzyme levels were normal.

A neuropathological review of the clival biopsies (along with the previous biopsies) was performed. Two specimens were obtained in March 2001. The first, measuring $1.0 \mathrm{~cm} \times 0.4 \mathrm{~cm} \times$ $0.3 \mathrm{~cm}$, was submitted for frozen section intraoperative diagnosis. This revealed fibrous stroma containing crushed small lymphoid cells and a localized aggregate of polymorphs. The remainder of the specimen was submitted for paraffin-embedded tissue processing. The second, measuring $1.0 \mathrm{~cm} \times 0.5 \mathrm{~cm} \times 0.2 \mathrm{~cm}$, was also submitted for paraffin-embedded tissue processing.

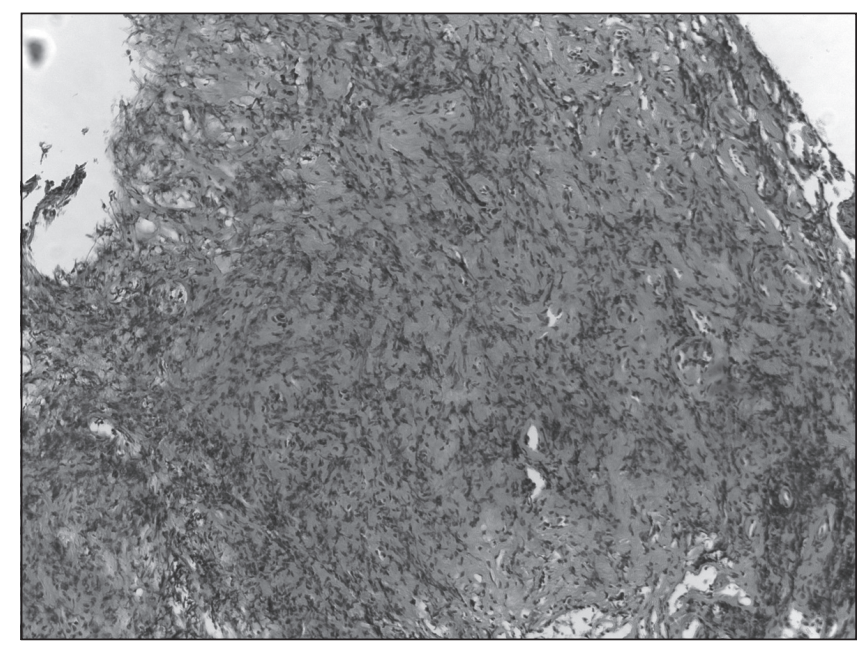

Figure 3) Partially crushed lymphoplasmacytic infiltrate associated with fibrosis (hematoxylin and eosin stain, original magnification $\times 100)$

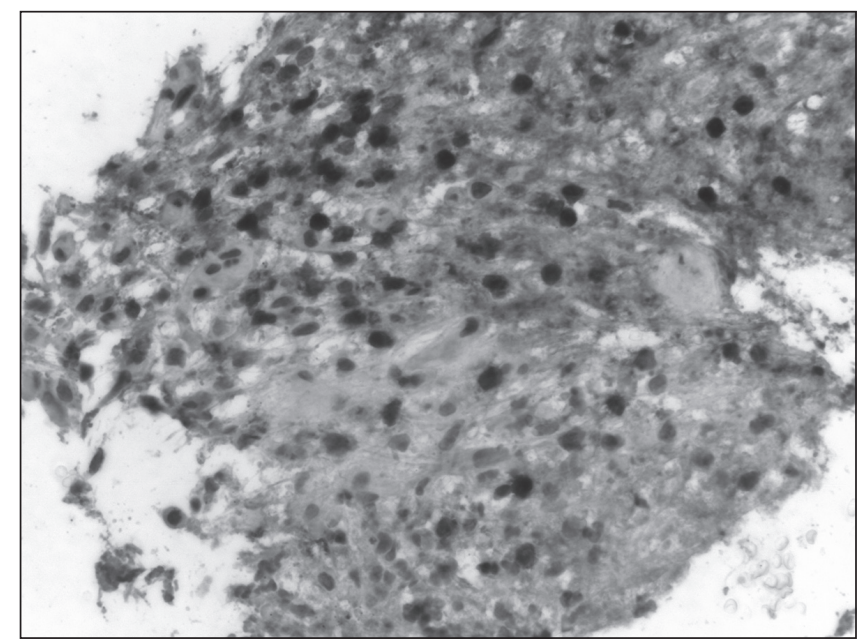

Figure 4) CD3 immunoperoxidase stain showing $T$ cell infiltrate (original magnification $\times 400$ )

Sections for microscopic evaluation revealed small pieces of fibrous-type tissue containing cellular lymphocytic infiltrates (Figure 3). Immunohistochemical studies confirmed the presence of $\mathrm{T}$ cells that were immunopositive for CD3 (Figure 4). Focal, nodular aggregates of B cells, immunoreactive for L26, were seen. Granulomatous inflammation with multinucleated giant cells was not defined in these fragments. There were also areas of varying cellularity, ranging from densely cellular to some hypocellular areas showing features suggestive of previous necrosis and resultant fibrosis. Special stains (Ziehl-Nielsen, Grocott's methamine silver, mucicarmine, Gram) revealed no bacterial, acid-fast or fungal organisms. Pathological interpretation was a reactive chronic inflammatory lesion with evidence of previous necrosis. Pathological differential diagnosis included an extraintestinal manifestation of inflammatory bowel disease or Wegener's granulomatosis with intestinal involvement.

During these in-hospital diagnostic studies, the patient developed rectal bleeding and diarrhea. Colitis had been previously diagnosed by a surgeon in a rural hospital approximately four years earlier, coinciding with the onset of his headaches 
and diplopia. His symptoms had previously responded to intermittent courses of steroid enemas, most recently required approximately three years earlier. Fecal cultures and fecal parasite studies were negative. Colonoscopy showed patchy inflammatory change throughout the colon with normal rectosigmoid mucosa, most consistent with Crohn's colitis. Numerous aphthoid and larger punched-out, linear and serpiginous ulcers were seen in the proximal colon, along with extensive pseudopolypoid changes. Biopsies in the proximal colon confirmed the presence of chronic inflammatory changes but no granulomatous inflammation was detected.

Other studies during the patient's hospitalization included a normal hemogram, with a hemoglobin of $123 \mathrm{~g} / \mathrm{L}$ and a white blood cell count of $9.9 \times 10^{9} / \mathrm{L}$. The patient's erythrocyte sedimentation rate was $27 \mathrm{~mm} / \mathrm{h}$. Electrolytes, renal function, protein, albumin and liver chemistry tests were normal. Thyroid and complement studies were normal. Antinuclear antibodies were negative and ANCA (including c-ANCA studies because of the suggestion of Wegener's disease) were negative $(4,5)$. The patient was initially treated with oral prednisone $100 \mathrm{mg}$ daily. His neurological and intestinal symptoms resolved and his steroids were gradually tapered and discontinued.

Over the next five years, he was treated with intermittent pulse steroid therapy for recurrent headache, diplopia and occasional bouts of concomitant bloody diarrhea in his local rural hospital. On each occasion, his symptoms completely resolved, with no recurrence of headache or diplopia. From 2006 to 2008, however, the patient was seen in four different hospitals in Vancouver and the lower mainland (British Columbia) for intermittent bloody diarrhea. Colonoscopies performed by six different gastroenterologists each confirmed the same endoscopic and histological findings believed to be most characteristic of Crohn's disease.

\section{DISCUSSION}

The present report documents an unusual sellar inflammatory mass associated with an extensive colonic inflammatory process clinically most characteristic of Crohn's disease. Most often, the majority of sellar masses represent neoplastic lesions. However, as in the present report, inflammatory sellar masses may also rarely occur and include lymphocytic hypophysitis, idiopathic giant cell hypophysitis and granulomatous hypophysitis. The latter include several diverse conditions, such as tuberculosis, sarcoidosis, Wegener's granulomatosis, syphilis and mycotic infections - all excluded in the present report. The appearance of a sellar inflammatory mass has been previously noted in Crohn's disease $(6,7)$. In one of these reports (6), it was hypothesized that the inflammatory mass - being granulomatous - may represent a form of extraintestinal granuloma in Crohn's disease or so-called 'metastatic' Crohn's disease (8). The latter is an uncommon entity reported elsewhere to occur in different sites separate from the gastrointestinal tract including skin $(8,9)$, muscle (10), genital tissues (11) and bone (12). Owing to the common embryological derivation of the pituitary gland and the gastrointestinal tract, an alternative and intriguing hypothesis may involve inflammatory processes developing in apparently separate but embryologically related sites.

Although the present experience appears to be unusual, it is conceivable that a more focal lymphocytic inflammatory process could occur in the sella with potentially significant clinical sequelae. Although overt neurological changes were evident in the present case, more subtle endocrine effects could occur with deficiencies in one or more pituitary hormones. Isolated adrenocorticotropic hormone deficiency has been associated with Crohn's disease, with the implication that the role for corticosteroids may extend beyond simply controlling the inflammatory process (13). Other pituitary hormone deficiencies may occur, including deficiencies of growth hormone and gonadotropins (14). These may, for example, have an important role to play in growth failure or sexual immaturity often seen with childhood Crohn's disease (15). Clearly, the hypothalamus and pituitary axis may be more significantly altered in patients with inflammatory bowel disease than is currently appreciated. Future neuroendocrine studies are needed to further elucidate these important clinical changes.

\section{REFERENCES}

1. Hansen I, Petrossians P, Thiry A, et al. Extensive inflammatory pseudotumor of the pituitary. J Clin Endocrinol Metab 2001;86:4603-10.

2. Glezer A, Paraiba DB, Bronstein MD. Rare sellar lesions. Endocrinol Metab Clin North Am 2008;37:195-211.

3. Sokol RJ, Farrell MK, McAdams AJ. An unusual presentation of Wegener's granulomatosis mimicking inflammatory bowel disease. Gastroenterology 1984;876:426-32.

4. Weir A, Taylor-Robinson SD, Poole S, Pignatelli M, Walters JFR, Calam J. Cytoplasmic antineutrophil cytoplasmic antibody positive vasculitis associated with ulcerative colitis. Am J Gastroenterol 1997;92:506-8.

5. Freeman HJ. Inflammatory bowel disease with cytoplasmic-staining antineutrophil cytoplasmic antibody and extensive colitis. Can J Gastroenterol 1998;12:279-82.

6. de Bruin WI, van't Verlaat JW, Graamans K, de Bruin TW. Sellar granulomatous mass in a pregnant woman with active Crohn's disease. Neth J Med 1991;39:136-41.

7. Ransley PG. Crohn's disease of Rathke's pouch? Guys Hosp Rep 1974;123:187-96.

8. McCallum DI, Gray WM. Metastatic Crohn's disease. Br J Dermatol 1976;95:551-4.

9. Sutphen JL, Cooper PH, Mackel SE, Nelson DL. Metastatic cutaneous Crohn's disease. Gastroenterology 1984;86:941-4.

10. Tweedie JH, McCann BG. Crohn's disease of the thigh and forearm. Gut 1984;25:213-4.

11. Freeman HJ, Kwong R, Sacks SL. Granulomatous vaginal ulceration due to metastatic cutaneous Crohn's disease. Can J Gastroenterol 1995;9:183-6.

12. Freeman HJ, Owen D, Millan M. Granulomatous osteonecrosis in Crohn's disease. Can J Gastroenterol 2000;14:951-4.

13. Kalambokis G, Vassiliou V, Vergos T, Christou L, Tsatsoulis A, Tsianos EV. Isolated ACTH deficiency associated with Crohn's disease. J Endocrinol Invest 2004;27:961-4.

14. Farthing MJ, Campbell CA, Walker-Smith J, Edwards CR, Rees LH, Dawson AM. Nocturnal growth hormone and gonadotrophin secretion in growth retarded children with Crohn's disease. Gut 1981;22:933-8.

15. Newby EA, Sawczenko A, Thomas AG, Wilson D. Interventions for growth failure in childhood Crohn's disease. Cochrane Database Syst Rev 2005:CD003873. 


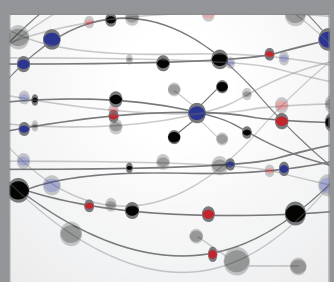

The Scientific World Journal
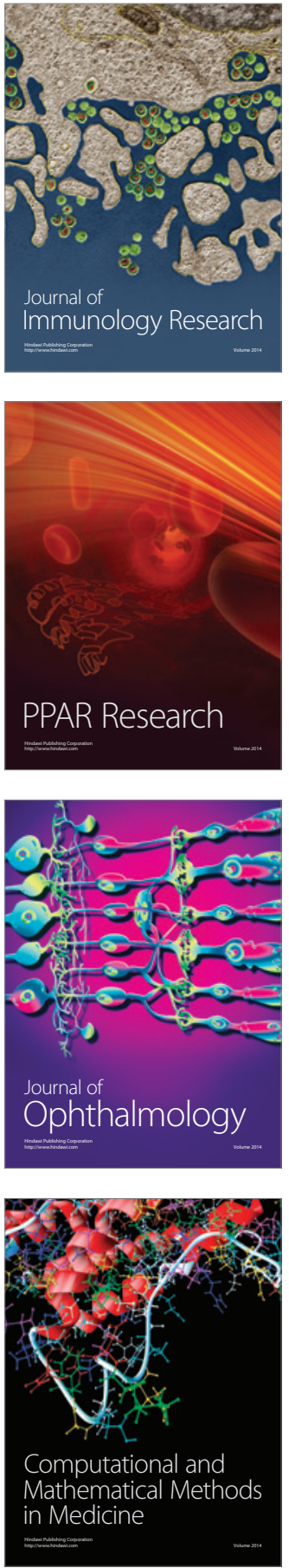

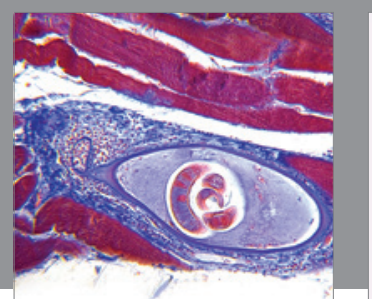

Gastroenterology Research and Practice

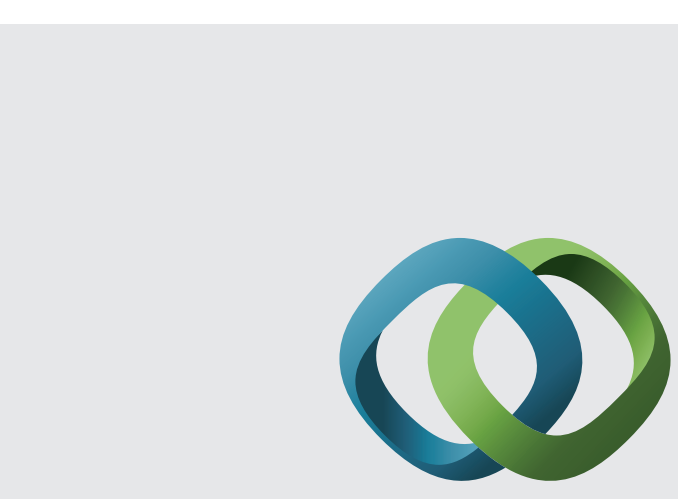

\section{Hindawi}

Submit your manuscripts at

http://www.hindawi.com
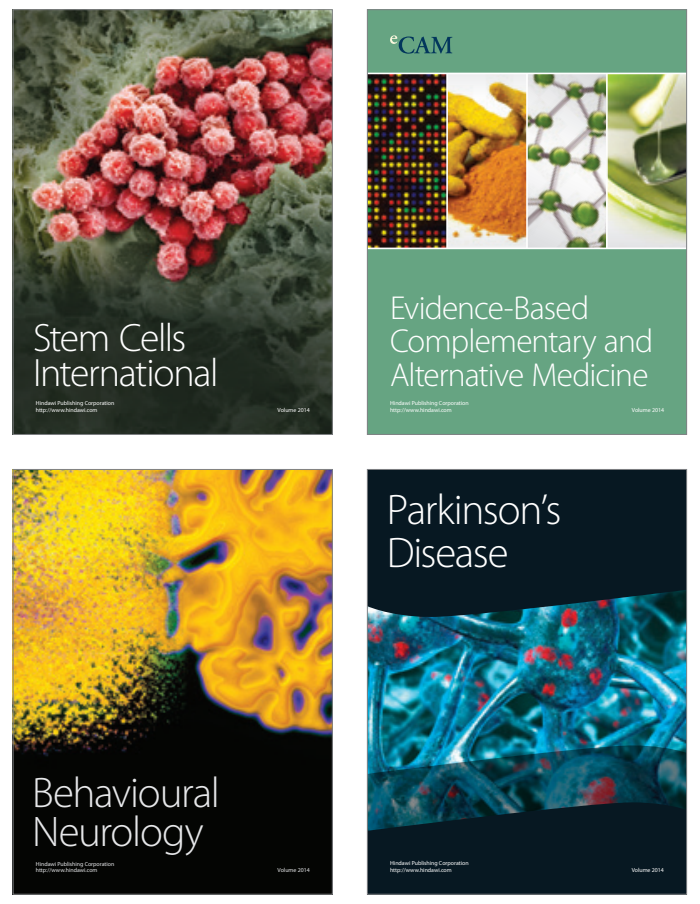
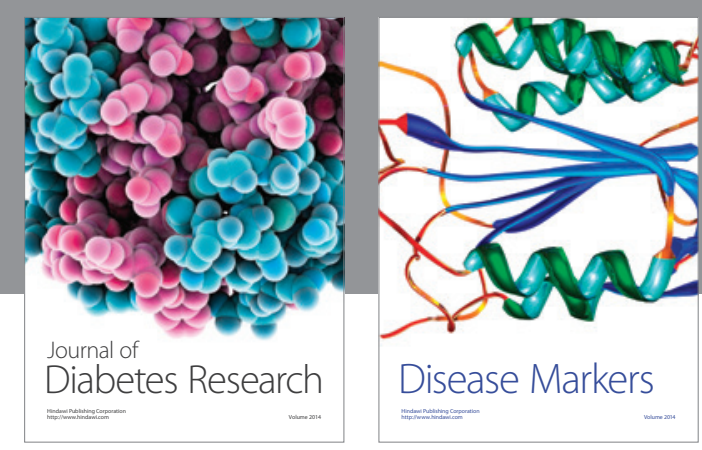

Disease Markers
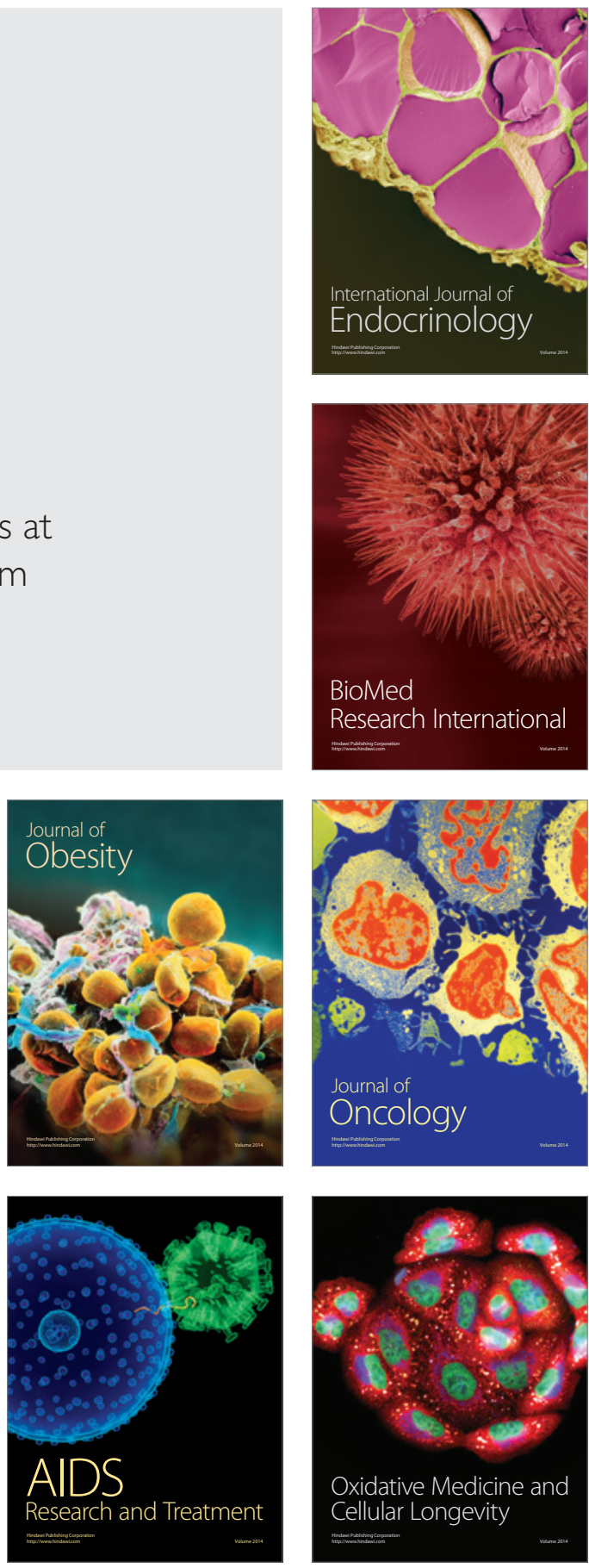